\title{
Cyber and In-Person Intimate Partner Violence Victimization: Examining Maladaptive Psychosocial and Behavioral Correlates
}

\author{
Lisa A. Melander ${ }^{1}$, Alison J. Marganski² \\ ${ }^{1}$ Kansas State University, Manhattan, Kansas, USA \\ 2 Le Moyne College, Syracuse, New York, USA
}

\begin{abstract}
This study examines psychological and behavioral correlates of cyber and in-person intimate partner victimization (IP-IPV; psychological, physical, and sexual violence) including strain (i.e., depression and anger), substance use, and antisocial behavior among young adults. Because intimate partner cyber aggression victimization (C-IPV) has received less research attention than IP-IPV, it is important to learn whether such victimization experiences are similar to in-person victimization experiences in terms of their associations with maladaptive functioning or whether they comprise a unique form of IPV. The study also explores strain as a potential mediator of the link between IPV victimization and maladaptive behavior. A sample of undergraduate students aged 18-25 who were in intimate relationships during the past year participated in a voluntary and anonymous online survey $(n=540)$. Results signaled that C-IPV and IP-IPV shared similar correlates (e.g. depression, substance use, and antisocial behavior) and C-IPV was linked with more forms of maladaptive behavior than certain types of in-person IPV victimization (e.g., sexual and physical) experiences. Results indicated partial support for the predicted mediation. Males were also at higher risk for engaging in substance use and antisocial behavior across all models. The study suggests that harmful electronic exchanges may have adverse consequences for young adults. As such, services providers and educators addressing the issue of IPV should tailor prevention and intervention strategies in a way that is inclusive of cyber aggression and considers it a public health concern.
\end{abstract}

Keywords: Cyber aggression; electronic aggression; intimate partner violence; substance use; antisocial behavior; strain theory

\section{Introduction}

Intimate partner violence (IPV), which generally refers to the threat or actual use of physical, sexual, and psychological aggression among romantic couples (Tjaden \& Thoennes, 2000), is a serious public health concern. This is particularly true for females (Rennison \& Welchans, 2000; Thompson et al., 2006; Tjaden \& Thoennes, 2000) who disproportionately experience in-person intimate partner violence victimization (IP-IPV) and those aged 18-24 (Breiding et al., 2014), which is the traditional age range of college students. Approximately 20-30\% of college students experience physical violence (Desmarais et al., 2012), 2-34\% are sexually assaulted (Fedina et al., 2018), and 70-90\% endure psychological aggression within intimate relationships each year in the United States (Shorey et al., 2008). Much research has been devoted to IPIPV (Breiding et al., 2014; Caldwell et al., 2012; Exner-Cortens et al., 2013; Hughes et al., 2010) however, less attention has been given to cyber intimate partner aggression victimization (C-IPV). C-IPV refers to the use of socially interactive technologies such as mobile phone text messaging and Internet-facilitated social networking (e.g., Facebook) by one individual to engage in controlling or harassing behavior against another (Marganski \& Melander, 2018). Although a few researchers have examined C-IPV in college samples (e.g. Borrajo et al., 2015; Marganski \& Melander, 2018), most research has been conducted with high school samples (Peskin et al., 2017; Temple et al., 2016; Van Ouytsel et al., 2016; 
Van Ouytsel et al., 2017). Given that a high percentage of university students date, C-IPV needs to be examined in university samples as well.

While the consequences of IP-IPV have been well documented (Exner-Cortens et al., 2013; Hughes et al., 2010), less attention has been given to C-IPV. Because different kinds of in-person experiences of IPV have resulted in similar sequelae (e.g. Coker et al., 2000, 2002; O'Leary, 1999) and violence occurs on a continuum, it is possible that C-IPV is associated with outcomes similar to IP-IPV (Lin et al., 2011). Individuals who experience IP-IPV may experience strain and engage in maladaptive coping such as antisocial behavior and substance use (Lu et al., 2018; Zweig et al., 2014). At this time, it is unknown whether or not this relationship exists for those experiencing C-IPV. IP-IPV has been linked to strain (e.g., depression and/or anger) which, in turn, may lead to maladaptive behaviors (Devries et al., 2014). Therefore, the current study aims to determine whether strain mediates the relationship between C-IPV and maladaptive behaviors among a college sample in the United States. Guided by Agnew (2001) and using recommendations by Baron and Kenny (1986), this study also examines whether strain, in the form of depression and anger, mediates the link between IPV victimization (i.e., C-IPV and IP-IPV) and maladaptive behavior, and whether gender differences exist. Taken together, the findings have important implications for service providers and educators who may need to enhance their programs to meet the needs of victims of C-IPV and/or IP-IPV.

\section{Technology \& IPV}

Interpersonal relationship communications have greatly evolved in recent years. Socially interactive technology (e.g. text messaging) is now a pervasive mode and standard means by which people interact with others (Kohut et al., 2011). With the increasing reliance on technology for our communications, researchers must investigate problematic relationship behaviors that transcend into the virtual world and what harm, if any, exists with this modern adaptation.

Technological advancements place one at close reach anytime and anywhere (Katz \& Aakhus, 2002), which is worrisome when considering the prevalence of IPV (Rennison \& Welchans, 2000; Tjaden \& Thoennes, 2000) and the ability of new media technologies to result in harm (David-Ferdon \& Hertz, 2007). Mobile phones are equipped with text messaging and social networking capacities, and it is easy to reach partners as well as a larger audience to use these platforms to control and harm others. News stories of GPS monitoring and tracking in current and former intimate relationships have become more common (Riegger \& Valiente, 2014; Wordsworth, 2015), along with cyber stalking, Internet harassment and public shaming (Kelly \& Segall, 2015; Marsden, 2016). Such technologies place partners in the same time and space, forming situational structures that open the door to unregulated harm whereby physically absent abusers may demean, degrade, intimidate, threaten, control, and/or stalk partners (Southworth et al., 2007; Spitzberg \& Hoobler, 2002). In support of this notion, researchers have found that C-IPV is not uncommon. It has been reported to occur in over $60 \%$ of a cross-cultural sample (Marganski \& Fauth, 2013), and in nearly three-quarters of college students (75\% - Borrajo et al., 2015; 73\% - Marganski \& Melander, 2018). This suggests that the prevalence of C-IPV may be higher than some IPIPV forms.

The boundaries between the cyber and real world have been blurred (Turkle, 2011), permitting individuals to express thoughts and feelings as they please, often without facing social cues. This online social disinhibition effect (Suler, 2004) may make the frequency of aggression, whether covert or overt, more common and it also may have the potential for more devastating consequences given its reach. Yet, it is possible that the recipient may not comprehend the sender's intentions (e.g. there was no malice) or the sender may not be cognizant of how the message impacts the recipient (e.g. whether someone was upset or harmed). Therefore, it is important in research on C-IPV to consider how individuals personally experience victimization and interpret these events.

Online victimization has a variety of offline consequences. C-IPV is associated with greater odds of IP-IPV (Marganski \& Melander, 2018; Reed et al., 2016; Timmons Fritz et al., 2018), and it is possible that these cyber behaviors are part of a larger violence nexus. Although physical harm is not a direct result of this form of violence, the consequences of psychological IP-IPV have been found to be at least as detrimental as other IP-IPV experiences (O'Leary, 1999) if not more damaging (Follingstad et al., 1990; Sev're, 2002). Sargent and colleagues (2016), for example, found that being victimized online by anyone was correlated with psychological IP-IPV, depression, and antisocial behavior among a sample of first-year college students. Given that our interactions now frequently occur via technology and there is evidence that C-IPV is a common (Marganski \& Melander, 2018; Temple et al., 2016; Timmons Fritz et al., 2018), distressful (Marganski, 2013) experience, it is important to learn more about its correlates. 


\section{C-IPV, Substance Use, and Antisocial Behaviors}

Although literature on general cyber aggression (Baum et al., 2009; Bocij, 2004; Ellison, 2001; Lydon et al., 2011) and CIPV (Bennett et al., 2011; Marganski \& Melander, 2018; Reed et al., 2016) is growing, the extant research does not provide much information on maladaptive behavioral outcomes or correlates that are associated with harmful online interactions. Researchers have conceptualized alcohol abuse, substance use, and antisocial behavior as predictors of cyber aggression perpetration and/or victimization in cross-sectional and longitudinal studies (Peskin et al., 2017; Temple et al., 2016; Van Ouytsel et al., 2016, 2017); however, few have examined the consequences of C-IPV among young adults.

Substance use and antisocial behavior are important correlates of IP-IPV (Exner-Cortens et al., 2013; Hughes et al., 2010), and researchers must consider whether such behaviors are also associated with C-IPV. C-IPV has been linked to poorer mental health (e.g., depression and anxiety), substance use, and higher levels of internalizing in cross-sectional samples (Lu et al., 2018; Timmons Fritz et al., 2018), and hard drug and marijuana use in longitudinal research (Lu et al., 2018). Wright and Li (2012) also found that C-IPV and IP-IPV were both longitudinally associated with cyber displaced aggression, which was defined as acting aggressively towards an innocent person to alleviate their anger and frustration. Finally, Zweig and colleagues (2014) examined teenage dating partners and suggested that experiences of C-IPV were linked to antisocial delinquent behaviors, sexual activity, depression, and anger. In their study, C-IPV was more strongly correlated with depression and delinquency than physical and psychological IP-IPV and general sexual coercion. Yet youth differ from young adults in that the latter group often leaves behind sources of social support (e.g. parents, friends) and enter new relationships within novel environments like college, which may make coping with strain more difficult (Arnett, 2000; Taylor et al., 2014).

Because of the limited research on correlates of C-IPV, it is critical that we conduct further research to expound upon potential impacts. Coping with adverse experiences can be challenging and may contribute to negative emotions and externalizing behaviors (e.g. Wright $\&$ Li, 2012). Individuals with limited resources or few prosocial coping skills may manage negative emotions by engaging in risky behaviors, which may be important to consider when the aggression is committed by an intimate partner. In other words, it is possible that IPV victimization creates strain that influences maladaptive behaviors.

\section{Gender Differences in IP-IPV and C-IPV}

Studies on IP-IPV have highlighted some gender differences. Research has suggested that females disproportionately experience more frequent and severe physical violence, sexual violence, and stalking behaviors (Black et al., 2011; Breiding et al., 2014; Coker et al., 2002) compared to their male counterparts. Females also suffer more with regards to injuries, fear, and posttraumatic stress disorder (PTSD) (Caldwell et al., 2012), causing them to develop safety concerns that impact their daily lives (Breiding et al., 2014). Previous research has found that females report more C-IPV than males (e.g. Marganski \& Fauth, 2013; Zweig et al., 2013), though others have failed to find gender differences with the exception of sex-related offenses (Reed et al., 2017) or have found men more likely to experience and perpetrate severe C-IPV (Zapor et al., 2017), perhaps as a byproduct of masculinity and "doing gender" as an ongoing and interactional process (West \& Zimmerman, 1987, p. 126).

Generally speaking, research has produced inconclusive and mixed results regarding how C-IPV impacts males and females. There is evidence that women report more distress in the aftermath of cyber aggression victimization than men (Bauman \& Newman, 2013; Reed et al., 2017) and view it to be more damaging to their reputation (Wyckoff et al., 2019). For instance, high school females more often than males have become upset and experience negative emotional responses to digital dating abuse victimization (Reed et al., 2017). In part, this may be due to larger cultural messages that women and girls receive that place pressure on them to please others via emphasized femininity (Connell, 1987) and internalize worth in terms of an ability to form and maintain relationships. Likewise, Bennett and colleagues (2011) found that for females, cyber aggression from peers and dating partners correlated with substance use and aggression, whereas peer cyber victimization was associated with only aggression for males. However, another study found a link between Internet harassment and depressive symptomology for males but not females (Ybarra, 2004). Finally, StubbsRichardson and colleagues (2018) found that girls may be more likely to engage in prosocial responses to high school cyber aggression than boys, while boys do not differ in terms of choosing prosocial or antisocial coping responses. Because of the conflicting results in these projects, more research is needed in the study of gender and the consequences of C-IPV. 


\section{General Strain Theory}

IP-IPV has been studied as a type of experience that influences and produces unanticipated harm to victims beyond the immediate damage inflicted by the partner (Kaufman, 2009). Underlying this is the concept of strain. Agnew (1992) stated that strain occurs within relationships where one is not being treated the way s/he would like to be (p. 48), which has the potential to translate into maladaptive and criminal coping for some individuals. General strain theory more broadly states that strain, or the anger or sadness one feels when needs are not met, can result from the presentation of noxious stimuli, which includes the presence of negative stimuli, removal of a positively valued stimuli, or failure to achieve positively valued goals (Agnew, 1992). Researchers have interpreted the concept of strain in varying ways, including studying objective and subjective strains (Agnew, 2001). Stressful life events, such as IPV, are those disliked by most members of a social group and may be considered objective social strains. These objective strains may, in turn, produce subjective strain, which refers to reactions to undesirable situations that may lead to negative conditions such as depression. Subjective strain may be differentially processed; for example, one individual might have an anger response to a stressful life event whereas another may become depressed when confronted with a similar experience (Agnew, 2001). These reactions can then contribute to nonconventional or nonconforming behavior, particularly when the originating strain is frequent, severe, or seen as unjust (Agnew, 2001). As such, objective strain produces negative emotional responses that may influence antisocial behavior.

Research on victims of IP-IPV has documented IPV as a stressful event that contributes to substance use and abuse among victims, the most common of which include alcohol and marijuana. Victims may drink alcohol, for instance, to cope with emotions resulting from victimization experiences (Gutierres \& Van Puymbroeck, 2006) or avoid the presence of recurring event exposure resulting from PTSD (Kaysen et al., 2007). Thus, objective strain (e.g. negative stimuli such as IPV victimizations) can trigger subjective strain (e.g. anger, depression), which then influences behavior. Prior research has supported this notion while offering insight into gender dynamics. Broidy and Agnew (1997) suggest that gender influences emotional reactions to subjective strain, which translates into distinct behavioral outcomes. While both males and females experience anger to stressful events, females were at greater risk for depression and internalizing behavior while males were at greater risk for externalization. The emotional responses, they argued, impacted subsequent behavior with males being at greater risk for crime, but the gender gap narrows for substance use.

Researchers have posited general strain theory as an explanation to account for the internalization and externalization of negative behaviors in cases of youth cyber victimization (see Hinduja \& Patchin, 2007; Wright \& Li, 2012). It is thought that victims may experience negative emotions that lead to maladaptive coping strategies including alcohol consumption, illicit drug use, and assault, among other behavioral problems. Previous research has established a link between certain individual-level stressors (e.g., C-IPV and anxiety) and depressive symptoms and anger (Wright, 2015; Zweig et al., 2014), yet research using adult samples is needed to confirm this relationship and consider whether specific subjective strains mediate the victimization-maladaptive coping link. If this is the case, then it may be important for clinicians to recognize and treat these conditions before symptoms manifest into harmful behaviors. Accordingly, this study will examine anger and depression as mediators of the link between IPV victimization and maladaptive behavior.

\section{Aim of the Study}

This study first investigates whether C-IPV and IP-IPV (psychological, physical, and sexual) relate to strain, substance use, and antisocial behavior. Because not much is known regarding C-IPV, the study examines both C-IPV and IP-IPV to consider correlates of each specific type of victimization and whether they resemble each other in terms of sharing criminogenic coping associations. We predict that C-IPV and all types of IP-IPV (i.e., psychological, physical, and sexual) will have similar correlates, and the presence of each type of victimization will relate to maladaptive functioning and behaviors. We also posit that strain, in the form of anger and depression, will mediate these relationships and we anticipate that these relationships will vary by gender based on the previously reviewed research (e.g. Bennett et al., 2011; Broidy \& Agnew, 1997; Reed et al., 2017). Specifically, we hypothesize:

$\mathrm{H}_{1}$ : IPV victimization (C-IPV, IP-IPV-Physical, IP-IPV-Psychological, and IP-IPV-Sexual) will be positively associated with substance use (e.g. problematic drinking, marijuana use, illicit drug use).

$\mathrm{H}_{2}$ : IPV will be positively associated with antisocial behavior.

$\mathrm{H}_{3}$ : Anger will mediate the relationship between IPV and substance use. 
$\mathrm{H}_{4}$ : Anger will mediate the relationship between IPV and antisocial behavior.

$\mathrm{H}_{5}$ : Depression will mediate the relationship between IPV and substance use.

$\mathrm{H}_{6}$ : Depression will mediate the relationship between IPV and antisocial behavior.

$\mathrm{H}_{7}$ : Females who experience IPV will be more likely to engage in substance use compared to males.

$\mathrm{H}_{8}$ : Males who experience IPV will be more likely to engage in antisocial behavior compared to females.

\section{Methods}

\section{Participants \& Procedures}

Following institutional ethics board approval, a sample of undergraduate students attending a large Midwestern university in the United States participated in a larger relationship survey conducted by the Marriage and Family Therapy department in 2014. All participants were enrolled in Marriage and Family Therapy or Criminology classes and given informed consent forms to learn about the study; if they chose to participate, they were then directed to a link to complete online surveys. Extra course credit was used to incentivize students, with a separate link containing information for extra credit following the survey. All surveys were completely voluntary and anonymous $(n=844)$. Age was restricted to those 18-25 years, and only those who reported being in a relationship in the past year were included in the analyses, leaving a final sample size of 540. This was done given the current study's focus on young adults in dating relationships. The sample consisted of mostly White $(90.0 \%)$ and female $(73.1 \%)$ students. The average age was $19(M=19.5, S D=$ 1.6), and most respondents were in only one relationship in the past year (79.0\%). Table 1 reports the sample characteristics, and there were no issues with missing data.

Table 1. Sample Characteristics $(N=540)$.

\begin{tabular}{|c|c|c|c|}
\hline & & \multicolumn{2}{|c|}{ Dichotomous Variables } \\
\hline & & $n$ & $\%$ \\
\hline \multicolumn{4}{|l|}{ Gender } \\
\hline Female & & 395 & 73.1 \\
\hline Male & & 145 & 26.9 \\
\hline \multicolumn{4}{|l|}{ Race } \\
\hline Non-white & & 54 & 10.0 \\
\hline White & & 486 & 90.0 \\
\hline \multicolumn{4}{|l|}{ Anger } \\
\hline No & & 356 & 65.9 \\
\hline \multirow[t]{3}{*}{ Yes } & & 184 & 34.1 \\
\hline & \multicolumn{3}{|c|}{ Continuous Variables } \\
\hline & $n$ & $M$ & $S D$ \\
\hline Age & 540 & 19.46 & 1.57 \\
\hline \# of relationships & 538 & 1.21 & 0.50 \\
\hline C-IPV & 540 & 7.49 & 7.25 \\
\hline IP-IPV-Psychological & 539 & 2.66 & 3.46 \\
\hline IP-IPV-Physical & 536 & 0.13 & 0.26 \\
\hline IP-IPV-Sexual & 540 & 0.08 & 0.19 \\
\hline Depression & 540 & 14.34 & 9.49 \\
\hline Problematic drinking & 539 & 2.72 & 2.85 \\
\hline Marijuana use & 538 & 1.18 & 1.98 \\
\hline Illicit drug use & 538 & 0.08 & 0.17 \\
\hline Antisocial behavior & 537 & 0.50 & 0.83 \\
\hline
\end{tabular}




\section{Measures}

C-IPV. Items in the C-IPV scale were largely based on data derived from focus groups on this topic (Melander, 2010), and from validated and modified measures found in cyberbullying and cyberstalking studies (Hinduja \& Patchin, 2007; Spitzberg \& Hoobler, 2002; Ybarra, 2004). The modified scale was previously piloted and evaluated for reliability and validity by a panel of experts conducting IPV research. Participants were asked 18 questions on how many times a current or former partner engaged in certain behaviors against them in the past year $(0=$ never $/$ not in the past year, $1=$ once, $2=$ twice, $\ldots 6=20$ times or more). These items were then combined into a summed measure (see Marganski \& Melander, 2018 for a complete list of items). Participants were asked, for example, if a partner posted poetry or music lyrics online to taunt or hurt them, sent them harassing images (e.g. pictures or videos of violence, nudity, etc.) through technology that made them uncomfortable, or shared personal/private images intended only for the partner with others electronically without the respondent's consent. Cronbach's alpha revealed high reliability for the variables used to construct C-IPV $(\alpha=.92)$.

IP-IPV. The items used to measure IP-IPV were from the Conflict Tactics Scale (see Straus et al., 1996). Participants were asked about behavior they experienced in-person in the past year $(0=$ never $/$ not in the past year, $1=$ once, $2=$ twice, $\ldots$ $6=20$ times or more) for measures comprising psychological, physical, and sexual violence. Cronbach's alpha was computed for IP-IPV-Psychological (8 items; e.g., "verbally told you who you could or could not hang out with," "called you derogatory names or insulted you in-person," "threatened to harm you in person by making a threatening statement," $\alpha=.87)$, IP-IPV-Physical (10 items; e.g., "grabbed you," "pushed or shoved you," "slapped you," $\alpha=.96)$, and IP-IPV-Sexual (2 items; "insisted on sex or used words to guilt you into having sex" and "used force or threats to make you have sex," $\alpha=.58$; intercorrelations = .49). The variables used to construct IP-IPV-Physical had excellent reliability and those for IP-IPV-Psychological had good reliability, but IP-IPV-Sexual had low reliability due to the item only having two measures, one minor and one severe. For the IP-IPV-Psychological, IP-IPV-Physical, and IP-IPV-Sexual measures, items comprising each form of victimization were summed. Log transformations were conducted for IP-IPV-Physical and IP-IPV-Sexual measures.

Behavioral correlates. Substance use (e.g. problematic drinking, marijuana use, illicit drug use) and antisocial behavior were also examined. For these behaviors, participants were asked about the amount of times they engaged in these behaviors in the past 12 months. Problematic drinking includes 6 items that were summed together (e.g., binge drinking, blacking out from drinking, and need a drink in the morning to get yourself going) which asked about behaviors in the past year $(0=$ never, $1=$ less than monthly, $\ldots 4=$ daily or almost daily) $(\alpha=.74)$. Marijuana use included one item on the frequency of marijuana consumption in the past year $(0=$ never, $1=$ once, $2=$ twice, $3=3-5$ times, $\ldots 6=20+$ times $)$. Illicit drug use consisted of three items (i.e., prescription drug use not intended for you, prescription drug overuse/abuse, and illegal hard drug use) with each measured on the same scale $(0=$ not in past year, $1=$ once, $2=$ twice, $3=3-5$ times $\ldots 6=20+$ times) $(\alpha=.75)$. The items were collapsed due to skew and then summed together. Log transformation was also performed. Antisocial behavior was measured with 5 items including theft, destruction of property, assault, carried weapon, and other illegal behavior $(0=$ not in past year, $1=$ once, $2=$ twice, $3=3-5$ times $\ldots 6=20+$ times $)(\alpha=.72)$. Each item was dichotomized ( $0=$ not in past year, $1=$ at least once in past year) and all items were summed together into one continuous measure that was then truncated (with scores ranging from $0-3$ ) to address skew.

Strain. In this study, strain was measured by asking about anger and depression. Respondents were asked about their reactions to experiencing C-IPV and IP-IPV, with response categories including anger, fear, insecurity, and devastation. To create the anger measure, the item that referenced "angry" was utilized $(0=$ no, $1=$ yes). Depression, also a subjective strain, was measured using 20 Center for Epidemiological Studies-Depression Scale items, which has documented reliability and validity (see Radloff, 1977). Responses categories included $0=$ rarely or none of the time, $2=$ some or a little of the time, $3=$ occasionally or a moderate amount of time, and $4=$ most or all of the time. Items were reversed coded when necessary so that a higher score indicates more frequent depressive symptoms $(\alpha=.90)$, and a summed item was created $(M=14.34, S D=9.49)$.

Demographics. Gender was measured by a single item indicator $(0=$ male, $1=$ female). Age (range $=18-25)$ and race $(0=$ non-White, $1=$ White) served as control variables. Number of relationships in the past year was measured and recoded $(0=0,1=1,2=2,3=3$ or more) due to skew. 


\section{Results}

\section{Bivariate Analyses}

Bivariate analyses were conducted to examine the relationship between all variables: IPV victimization experiences (CIPV and IP-IPV-Psychological, IP-IPV-Physical, and IP-IPV-Sexual), the mediator variables of anger and depression, and dependent variables of interest including marijuana use, problematic drinking, hard drug use, and antisocial behavior. Because $p$ values assume normally distributed data, bootstrapping was performed with 1000 samples and bias corrected accelerated (BCA) was used; the $95 \%$ confidence interval helped verify the $p$-value and significance (Table 2). Overall, the results generally show IPV victimization was positively associated with problem behavior; IPV was positively associated with strain; and strain was positively associated with problem behaviors. Being male was associated with anger, IP-IPVPhysical, and problem behaviors whereas being female was associated with IP-IPV-Sexual. Older age was associated with more substance use and antisocial behavior whereas being White was associated with less depressive symptoms, IP-IPVSexual, and antisocial behavior.

Table 2. Correlations for Characteristics, Forms of IPV Victimization, and Maladaptive Behaviors $(N=540)$.

\begin{tabular}{|c|c|c|c|c|c|c|c|c|c|c|c|c|c|c|}
\hline & (1) & (2) & (3) & (4) & (5) & (6) & (7) & (8) & (9) & $(10)$ & $(11)$ & $(12)$ & (13) & (14) \\
\hline (1) Age & 1.0 & & & & & & & & & & & & & \\
\hline (2) Gender & $-.21^{\star \star}$ & 1.0 & & & & & & & & & & & & \\
\hline (3) Race & $-.13^{\star \star}$ & .04 & 1.0 & & & & & & & & & & & \\
\hline (4) \# Relationships & -.08 & .08 & -.05 & 1.0 & & & & & & & & & & \\
\hline $\begin{array}{l}\text { (5) Depressive } \\
\text { Sympt. }\end{array}$ & .00 & -.03 & $-.18^{\star \star}$ & -.01 & 1.0 & & & & & & & & & \\
\hline (6) Anger & -.01 & $-.11^{*}$ & -.06 & $.11^{*}$ & $.10^{\star}$ & 1.0 & & & & & & & & \\
\hline (7) C-IPV & -.05 & .04 & -.04 & .08 & $.17^{\star \star}$ & $.367^{\star}$ & 1.0 & & & & & & & \\
\hline (8) IP-IPV-Psych. & -.03 & .04 & -.07 & .07 & $.19^{\star *}$ & $.48^{\star \star}$ & $.70^{\star \star}$ & 1.0 & & & & & & \\
\hline (9) IP-IPV-Physical & .04 & $-.13^{* *}$ & -.08 & $.12^{\star *}$ & $.19 * \star$ & $.32^{\star *}$ & $.52^{\star \star}$ & $.58^{\star \star}$ & 1.0 & & & & & \\
\hline (10) IP-IPV-Sexual & -.06 & $.11^{\star *}$ & $-.09 *$ & .06 & $.15^{\star \star}$ & $.22^{\star \star}$ & $.38^{\star \star}$ & $.51^{\star \star}$ & $.40^{\star \star}$ & 1.0 & & & & \\
\hline $\begin{array}{l}\text { (11) Problem } \\
\text { Drinking }\end{array}$ & $.13^{\star \star}$ & $-.19^{* \star}$ & .03 & .04 & $.18^{\star \star}$ & $.09^{*}$ & $.13^{\star \star}$ & $.13^{\star *}$ & $.10^{\star}$ & -.01 & 1.0 & & & \\
\hline (12) Marijuana Use & -.01 & $-.11^{*}$ & -.02 & .05 & $.12^{\star *}$ & $.10^{\star}$ & $.14^{\star *}$ & $.15^{* *}$ & $.11^{* *}$ & .07 & $.35^{\star *}$ & 1.0 & & \\
\hline (13) Illicit Drug Use & $.16^{\star \star}$ & $-.17^{\star \star}$ & -.08 & .02 & $.20^{\star *}$ & .08 & $.10^{*}$ & $.14^{\star \star}$ & $.14^{\star \star}$ & $.13^{\star *}$ & $.35^{\star \star}$ & $.54^{\star \star}$ & 1.0 & \\
\hline $\begin{array}{l}\text { (14) Antisocial } \\
\text { Behavior }\end{array}$ & $.16^{\star \star}$ & $-.25^{\star *}$ & $-.11^{\star}$ & -.05 & $.18^{\star \star}$ & .05 & $.16^{\star \star}$ & $.23^{\star *}$ & $.22^{\star \star}$ & $.18^{\star \star}$ & $.35^{\star \star}$ & $.32^{* *}$ & $.55^{\star \star}$ & 1.0 \\
\hline
\end{tabular}

Note. For gender, $0=$ male and $1=$ female.

${ }^{*} p<.05,{ }^{*} p<.01,{ }^{* *} p<.001$.

\section{Mediation Models}

Because we are interested in the possible mediating effects of strain, the study explores whether anger and/or depression impacts the link between IPV victimizations and maladaptive behaviors using procedures recommended by Baron and Kenny (1986) as well as James and Brett (1984). To determine if mediation exits, three conditions must be met. For Condition 1, direct effects between the independent variables (C-IPV, IP-IPV-Psychological, IP-IPV-Physical, and IP-IPVSexual) and the dependent variables (problematic drinking, marijuana use, illicit drug use, and antisocial behavior) must be established. If this condition is met, Condition 2 requires a relationship between the independent variables (C-IPV, IPIPV-Psychological, IP-IPV-Physical, and IP-IPV-Sexual) and the mediator (anger and depression). If significance has been established, Condition 3 requires that, controlling for independent variables, there is a relationship between the mediator and the dependent variable, with the effects of the independent variable decreased. This provides evidence of complete or partial mediation. Because of the complexity of these procedures and due to the aforementioned hypotheses (e.g. $\mathrm{H}_{3}-\mathrm{H}_{6}$ ), separate analyses were conducted for anger and for depression to test for potentially mediating relationships on IPV type and maladaptive behavior (see Figure 1). 


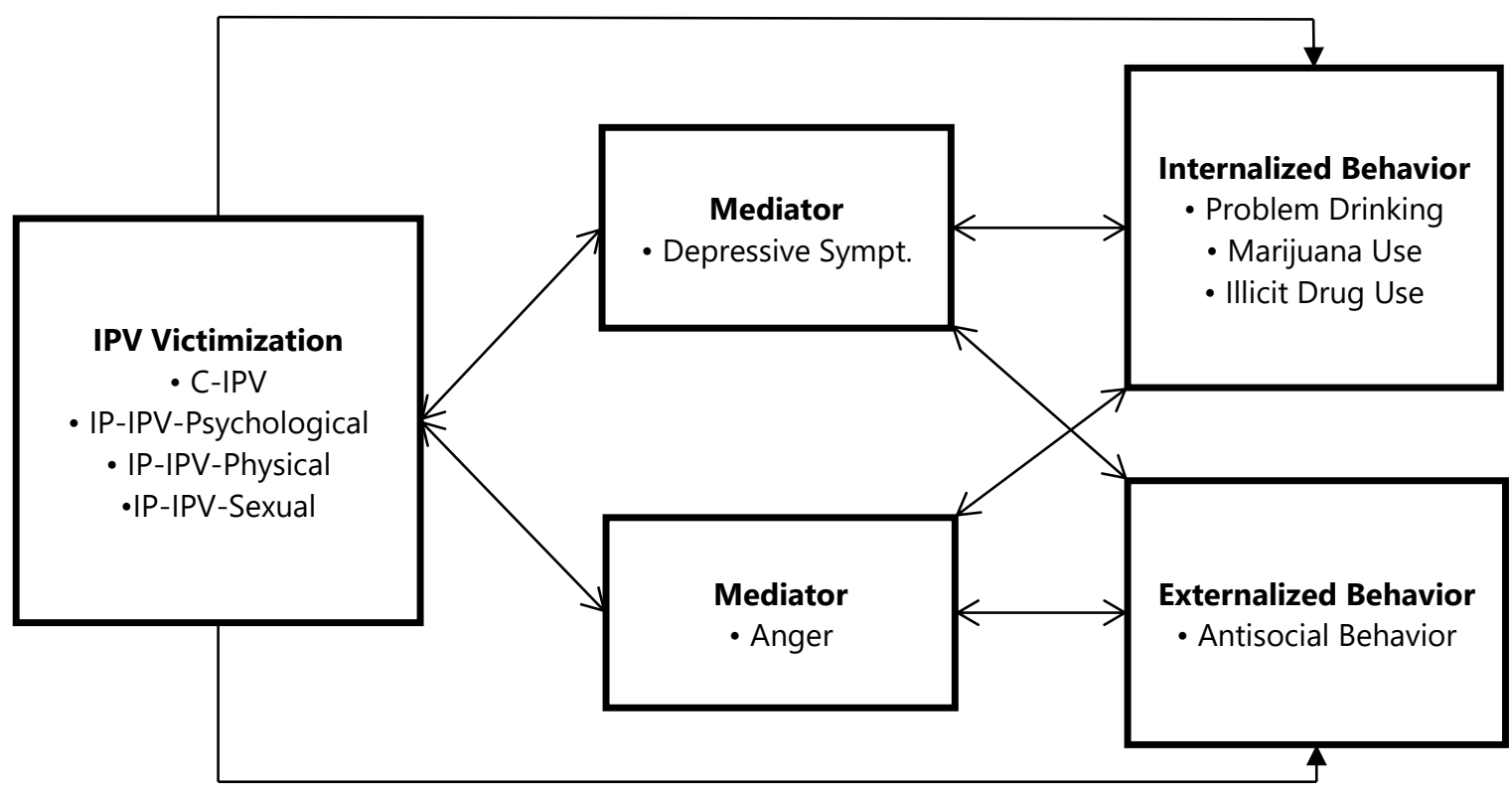

Figure 1. Mediational model of IPV victimization, strain, and offending behavior.

To begin the mediation tests (i.e., Condition 1), direct effects between the independent and dependent variables must be established. We tested for this by running a series of OLS regression models (see Model 1 in Tables 3-6). These analyses were identical for the models examining anger and depression as mediators because only the relationship between IPV types (C-IPV, IP-IPV-Psychological, IP-IPV-Physical, and IP-IPV-Sexual) and behaviors (problem drinking, marijuana use, illicit drug use, and antisocial behavior) were examined in the first step. The results show that, in general, C-IPV and IP-IPV-Psychological, IP-IPV-Physical, and IP-IPV-Sexual were positively associated with each behavioral variable. For example, experiencing more $C$-IPV was associated with more problematic drinking $(\beta=.138, p=.001)$, marijuana use $(\beta=.141, p=.001)$, illicit drug use $(\beta=.107, p=.012)$, and antisocial behavior $(\beta=.150, p=.000)$. However, the relationship between IP-IPV-Physical and problematic drinking, and IP-IPV-Sexual and problematic drinking and marijuana use were not significant; therefore, they did not meet the first condition necessary for mediation. Conditions 2 and 3 were tested for anger and depression as separate mediators with descriptions and results presented below.

Anger as a mediator. For Condition 2, a significant relationship must exist between the independent variable and mediator. Because the anger measure was dichotomous, a series of logistic regression analyses were conducted (results not shown). All IPV measures (C-IPV, IP-IPV-Psychological, IP-IPV-Physical, and IP-IPV-Sexual) were positively and significantly associated with anger, thereby meeting Condition 2. For example, experiencing more C-IPV was related to more anger $(\operatorname{Exp}(B)=1.12, p=.000)$ as was IP-IPV-Psychological $\operatorname{Exp}(B)=1.36, p=.000)$, IP-IPV-Physical $(\operatorname{Exp}(B)=16.75$, $p=.000)$ and IP-IPV-Sexual $(\operatorname{Exp}(B)=8.52, p=.000)$.

For Condition 3, a relationship must exist between the mediator and dependent variable see Model 2, Tables 3-6), with the effects of the independent variable decreased (see Model 1 to Model 2 changes in Tables 3-6). There was no support for mediation across any of the anger models, thereby failing to meet Condition 3 . In some models, anger was significant, namely for IP-IPV-Physical and IP-IPV-Sexual and problematic drinking, and for IP-IPV-Sexual marijuana use, but the IPV form was not in the initial or the final model. However, all four forms of IPV (C-IPV and IP-IPV-Psychological, IP-IPVPhysical, and IP-IPV-Sexual) were related to illicit drug use and antisocial behavior. Also, two of these forms, C-IPV and IP-IPV-Psychological, were significantly associated with all four outcome variables with more victimization being associated with more problematic drinking, marijuana use, illicit drug use, and antisocial behavior (IP-IPV-Physical and IP-IPV-Sexual each only related to two: illicit drug use and antisocial behavior). Males were also at greater risk for all outcome variables for all models. For example, males were more likely to engage in antisocial behavior in the models where C-IPV $(\beta=-.260, p=.000)$, IP-IPV-Psychological $(\beta=-.258, p=.000)$, IP-IPV-Physical $(\beta=-.235, p=.000)$, and IPIPV-Sexual $(\beta=-.275, p=.000)$ were considered independent variables.

Depression as a mediator. To establish Condition 2, a series of OLS regression analyses with the IPV independent variables and depression as a dependent variable were conducted (results not shown). The findings suggest that all IPV measures (C-IPV, IP-IPV-Psychological, IP-IPV-Physical, and IP-IPV-Sexual) were positively and significantly associated with depression $(\operatorname{Exp}(B)=0.176, p=.000 ; \operatorname{Exp}(B)=0.187, p=.000 ; \operatorname{Exp}(B)=0.190, p=.000 ; \operatorname{Exp}(B)=0.154, p=.001$, 
respectively). For example, experiencing more sexual violence (IP-IPV-Sexual) was associated with more depression ( $\beta=$ $.154, p=.001)$.

The final step for mediation requires a significant relationship between the mediator and dependent variable, with the effects of the independent variable decreased (see changes from Model 1 to Model 2 in Tables 3-6). One model revealed that the effect of IP-IPV-Physical victimization on marijuana use was no longer significant due to the introduction of depression ( $\beta=.086, p=.051$ ). Additionally, the effect of C-IPV victimization on illicit drug use disappeared when depression was included. Partial mediation was established for several models, including C-IPV and IP-IPV-Psychological and problematic drinking; C-IPV and IP-IPV-Psychological and marijuana use; IP-IPV-Psychological, IP-IPV-Physical, and IP-IPV-Sexual and illicit drug use; and C-IPV, IP-IPV-Psychological, IP-IPV-Physical, and IP-IPV-Sexual and antisocial behavior. All four forms of IPV (C-IPV and IP-IPV-Psychological, -Physical, and -Sexual) were related to antisocial behavior. IP-IPV-Psychological was the only IPV form found significant across all outcomes of interest, and C-IPV was significant in three of the four outcomes. Specifically, IP-IPV-Psychological was significantly associated with problematic drinking, marijuana use, illicit drug use, and antisocial behavior, while C-IPV was associated with problematic drinking, marijuana use, and antisocial behavior (illicit drug use lost significance for C-IPV from Model 1 to 2 when depression was added). IP-IPV-Sexual was related to illicit drug use and antisocial behavior while IP-IPV-Physical related only to illicit drug use. As with the anger mediation models, males were significantly more likely to be at risk for all problem behaviors in the depression models. See Tables 3-6 for the results of all multivariate analyses.

Table 3. Standardized Regressions Predicting Problematic Drinking.

\begin{tabular}{|c|c|c|c|c|c|c|c|c|c|c|c|c|c|c|c|c|}
\hline \multirow{2}{*}{ Model } & \multicolumn{4}{|c|}{ Cyber } & \multicolumn{4}{|c|}{ Psychological } & \multicolumn{4}{|c|}{ Physical } & \multicolumn{4}{|c|}{ Sexual } \\
\hline & M1 & $p$ & $\mathrm{M} 2$ & $p$ & M1 & $p$ & $\mathrm{M} 2$ & $p$ & M1 & $p$ & M2 & $p$ & M1 & $p$ & M2 & $p$ \\
\hline \multicolumn{17}{|l|}{ Anger Mediation } \\
\hline Female & .202 & .000 & -.209 & .000 & -.201 & .000 & -.207 & .000 & -.186 & .000 & -.202 & .000 & -.199 & .000 & -.209 & .000 \\
\hline IPV form & .138 & .001 & .111 & .014 & .140 & .001 & .108 & .023 & .072 & .093 & .036 & .432 & .014 & .736 & -.010 & .817 \\
\hline Anger & & & .075 & .096 & & & .067 & .165 & & & .104 & .021 & & & .118 & .007 \\
\hline Change in $\mathrm{F}$ & 10.89 & & 2.781 & & 11.099 & & 1.929 & & 2.829 & & 5.354 & & .114 & & 7.442 & \\
\hline Total adjusted $\mathrm{R}^{2}$ & .055 & & .058 & & .055 & & .056 & & .040 & & .048 & & .036 & & .047 & \\
\hline \multicolumn{17}{|c|}{ Depression Mediation } \\
\hline Female & .202 & .000 & -.196 & .000 & -.201 & .000 & -.195 & .000 & -.186 & .000 & -.184 & .000 & -.199 & .000 & -.190 & .000 \\
\hline IPV & .138 & .001 & .111 & .009 & .140 & .001 & .111 & .009 & .072 & .093 & .038 & .372 & .014 & .736 & .013 & .759 \\
\hline Depression & & & .157 & .000 & & & .154 & .000 & & & .178 & .000 & & & .179 & .000 \\
\hline Change in $\mathrm{F}$ & 10.89 & & 13.955 & & 11.099 & & 13.316 & & 2.829 & & 17.460 & & .114 & & 17.900 & \\
\hline Total adjusted $\mathrm{R}^{2}$ & .055 & & .077 & & .055 & & .076 & & .040 & & .069 & & .036 & & .065 & \\
\hline
\end{tabular}

Table 4. Standardized Regressions Predicting Marijuana.

\begin{tabular}{|c|c|c|c|c|c|c|c|c|c|c|c|c|c|c|c|c|}
\hline \multirow{2}{*}{ Model } & \multicolumn{4}{|c|}{ Cyber } & \multicolumn{4}{|c|}{ Psychological } & \multicolumn{4}{|c|}{ Physical } & \multicolumn{4}{|c|}{ Sexual } \\
\hline & M1 & $p$ & M2 & $p$ & M1 & $p$ & M2 & $p$ & M1 & $p$ & M2 & $p$ & M1 & $p$ & M2 & $p$ \\
\hline \multicolumn{17}{|l|}{ Anger Mediation } \\
\hline Female & -.105 & .014 & -.112 & .009 & -.108 & .011 & -.113 & .009 & -.090 & .038 & -.103 & .019 & -.109 & .012 & -.117 & .007 \\
\hline IPV & .141 & .001 & .114 & .013 & .152 & .000 & .129 & .008 & .103 & .018 & .073 & .115 & .082 & .059 & .060 & .174 \\
\hline Anger & & & .074 & .110 & & & .049 & .315 & & & .088 & .056 & & & .103 & .019 \\
\hline Change in $F$ & 10.948 & & 2.565 & & 12.817 & & 1.011 & & 5.649 & & 3.66 & & 3.581 & & 5.494 & \\
\hline Total adjusted $R^{2}$ & .026 & & .029 & & .030 & & .030 & & .017 & & .022 & & .013 & & .021 & \\
\hline \multicolumn{17}{|c|}{ Depression Mediation } \\
\hline Female & -.105 & .014 & -.102 & .017 & -.108 & .011 & -.105 & .013 & -.090 & .038 & -.089 & .039 & -.109 & .012 & -.104 & .016 \\
\hline IPV & .141 & .001 & .125 & .004 & .152 & .000 & .135 & .002 & .103 & .018 & .086 & .051 & .082 & .059 & .066 & .128 \\
\hline Depression & & & .097 & .025 & & & .100 & .020 & & & .094 & .031 & & & .109 & .012 \\
\hline Change in $F$ & 10.948 & & 5.056 & & 12.817 & & 5.408 & & 5.649 & & 4.705 & & 3.581 & & 6.334 & \\
\hline Total adjusted $R^{2}$ & .026 & & .033 & & .030 & & .038 & & .017 & & .024 & & .013 & & .023 & \\
\hline
\end{tabular}


Table 5. Standardized Regressions Predicting Illicit Drug Use.

\begin{tabular}{|c|c|c|c|c|c|c|c|c|c|c|c|c|c|c|c|c|}
\hline \multirow{2}{*}{ Model } & \multicolumn{4}{|c|}{ Cyber } & \multicolumn{4}{|c|}{ Psychological } & \multicolumn{4}{|c|}{ Physical } & \multicolumn{4}{|c|}{ Sexual } \\
\hline & M1 & $p$ & $\mathrm{M} 2$ & $p$ & M1 & $p$ & M2 & $p$ & M1 & $p$ & $\mathrm{M} 2$ & $p$ & M1 & $p$ & $\mathrm{M} 2$ & $p$ \\
\hline \multicolumn{17}{|l|}{ Anger Mediation } \\
\hline Female & -.164 & .000 & -.170 & .000 & -.167 & .000 & -.170 & .000 & -.147 & .001 & -.155 & .000 & -.176 & .000 & -.182 & .000 \\
\hline IPV & .107 & .012 & .082 & .071 & .148 & .000 & .134 & .006 & .118 & .006 & .098 & .033 & .146 & .001 & .131 & .003 \\
\hline Anger & & & .068 & .137 & & & .031 & .523 & & & .060 & .190 & & & .071 & .104 \\
\hline Change in $F$ & 6.377 & & 2.213 & & 12.322 & & .408 & & 7.623 & & 1.721 & & 11.877 & & 2.657 & \\
\hline Total adjusted $R^{2}$ & .033 & & .035 & & .044 & & .043 & & .036 & & .038 & & .043 & & .046 & \\
\hline \multicolumn{17}{|c|}{ Depression Mediation } \\
\hline Female & -.164 & .000 & -.157 & .000 & -.167 & .000 & -.161 & .000 & -.147 & .001 & -.145 & .001 & -.176 & .000 & -.168 & .000 \\
\hline IPV & .107 & .012 & .076 & .075 & .148 & .000 & .116 & .006 & .118 & .006 & .086 & .044 & .146 & .001 & .120 & .005 \\
\hline Depression & & & .187 & .000 & & & .184 & .000 & & & .176 & .000 & & & .183 & .000 \\
\hline Change in $F$ & 6.377 & & 19.54 & & 12.322 & & 18.975 & & 7.623 & & 17.002 & & 11.877 & & 18.989 & \\
\hline Total adjusted $R^{2}$ & .033 & & .066 & & .044 & & .075 & & .036 & & .064 & & .043 & & .074 & \\
\hline
\end{tabular}

Table 6. Standardized Regressions Predicting ASB

\begin{tabular}{|c|c|c|c|c|c|c|c|c|c|c|c|c|c|c|c|c|}
\hline \multirow{2}{*}{ Model } & \multicolumn{4}{|c|}{ Cyber } & \multicolumn{4}{|c|}{ Psychological } & \multicolumn{4}{|c|}{ Physical } & \multicolumn{4}{|c|}{ Sexual } \\
\hline & M1 & $p$ & $\mathrm{M} 2$ & $p$ & M1 & $p$ & $\mathrm{M} 2$ & $p$ & M1 & $p$ & $\mathrm{M} 2$ & $p$ & M1 & $p$ & $\mathrm{M} 2$ & $p$ \\
\hline \multicolumn{17}{|l|}{ Anger Mediation } \\
\hline Female & -.259 & .000 & -.260 & .000 & -.261 & .000 & -.258 & .000 & -.233 & .000 & -.235 & .000 & -.272 & .000 & -.275 & .000 \\
\hline IPV & .150 & .000 & .143 & .001 & .215 & .000 & .234 & .000 & .167 & .000 & .162 & .000 & .171 & .000 & .163 & .000 \\
\hline Anger & & & .020 & .655 & & & -.039 & .409 & & & .012 & .780 & & & .038 & .369 \\
\hline Change in $F$ & 13.18 & & .200 & & 27.694 & & .683 & & 15.953 & & .078 & & 17.059 & & .810 & \\
\hline Total adjusted $R^{2}$ & .083 & & .082 & & .106 & & .106 & & .088 & & .087 & & .089 & & .089 & \\
\hline \multicolumn{17}{|c|}{ Depression Mediation } \\
\hline Female & -.259 & .000 & -.254 & .000 & -.261 & .000 & -.257 & .000 & -.233 & .000 & -.232 & .000 & -.272 & .000 & -.266 & .000 \\
\hline IPV & .150 & .000 & .126 & .003 & .215 & .000 & .192 & .000 & .167 & .000 & .143 & .001 & .171 & .000 & .151 & .000 \\
\hline Depression & & & .142 & .001 & & & .129 & .002 & & & .131 & .002 & & & .142 & .001 \\
\hline Change in $F$ & 13.18 & & 11.742 & & 27.694 & & 9.756 & & 15.953 & & 9.873 & & 17.059 & & 11.918 & \\
\hline Total adjusted $R^{2}$ & .083 & & .101 & & .106 & & .121 & & .088 & & .103 & & .089 & & .108 & \\
\hline
\end{tabular}

\section{Discussion}

IPV experiences have been found to be very harmful to victims (Exner-Cortens et al., 2013; Hughes et al., 2010); however, much of the current literature focuses solely on the impact of IP-IPV experiences and neglects consideration of harmful behaviors that occur online between partners. It is important to determine the correlates of C-IPV, especially given the proliferation of newer technological communication methods that provide continuous contact between victims and offenders. As such, the purpose of the current study was to examine the independent effects of C-IPV and IP-IPV (i.e., psychological, physical, and sexual) on negative behavioral correlates and to learn whether anger and/or depression mediated the relationship between different forms of C-IPV and IP-IPV and problematic drinking, marijuana use, illicit drug use, and antisocial behavior. The main results and policy implications are considered below. 


\section{IPV and Maladaptive Functioning and Behavior}

First, the study set out to explore whether C-IPV and IP-IPV had similar behavioral correlates. The findings of the study generally supported this. Results show that C-IPV and physical, psychological, and sexual IP-IPV were each positively associated with behavior variables. Further, C-IPV resembled psychological IP-IPV in terms of associated correlates, as these forms of IPV were related to problematic drinking, marijuana use, illicit drug use, and antisocial behavior; physical and sexual IP-IPV were related to fewer of the behavioral variables explored. Some non-significant relationships were also observed (i.e., physical IP-IPV and problem drinking, and sexual IP-IPV and problem drinking and marijuana use). It is possible that some persons who experience such victimization engage in problem drinking and/or marijuana use to cope with these adverse circumstances, which has been found in previous literature (Lu et al., 2018; Zweig et al., 2014). Other victims may not engage in these behaviors, potentially in an effort to reduce the risk future victimization experiences (Palmer et al., 2010). Furthermore, physical and sexual IPV tend to receive more targeted attention when it comes to risk reduction strategies as well as victim blaming. The reasons for this are unclear and should be further studied. Nevertheless, the findings suggest that C-IPV was similar to IP-IPV, especially psychological IP-IPV, in that it was related to substance use and antisocial behavior, thereby supporting the first two hypotheses $\left(\mathrm{H}_{1}\right.$ and $\left.\mathrm{H}_{2}\right)$. This is in line with existing research that has found a relationship between IPV and maladaptive behavior (e.g. Lu et al., 2018; Timmons Fritz et al., 2018; Van Ouystel et al., 2016; Wright \& Li, 2012; Zweig et al., 2014) and the commonalities between C-IPV and IP-IPV-Psychological (Melander, 2010; Sargent et al., 2016), which is perhaps because these are both non-contact forms of aggression.

The findings also suggested that IPV (i.e., C-IPV and IP-IPV) was related to strain in the forms of anger and depression. While limited research exists on adult samples as related to partner violence and strain, the results reflect findings that have been documented for youth (Wright, 2015; Zweig et al., 2014).

\section{Anger as a Mediator}

To test the third and fourth hypotheses, anger was examined as a mediator between IPV (C-IPV and IP-IPV) and substance use (i.e., problematic drinking, marijuana use, and illicit drug use) and between IPV and antisocial behavior to see if any significant findings emerged $\left(\mathrm{H}_{4}\right)$. Hypotheses 3 and 4 were not supported. Anger resulting from IPV experiences did not mediate the victimization-maladaptive coping connection, which could be due to the availability of only one-item anger measure in this dataset. It is also possible that IPV victims face stigma and victim-blaming from others, which has been found to lead to avoidance coping and depression rather than anger (Overstreet et al., 2019). This type of state anger, however, was related to IPV victimization and to behavioral issues.

Although anger was not found to mediate the relationships between IPV and substance use or antisocial behavior, there were still some important and significant relationships. Psychological IP-IPV was associated with all substance use types and antisocial behavior, as was C-IPV (although C-IPV lost significance in Model 2). Physical and sexual IP-IPV, on the other hand, were only significantly associated with illicit drug use and antisocial behavior. Thus, while it is a new area of study, C-IPV should continue to be explored in IPV research as it was associated with correlates similar to those noted for psychological IP-IPV and related to more maladaptive behaviors than two other forms of IP-IPV. This finding is consistent with studies in the broader literature (Lu et al., 2018; Timmons Fritz et al., 2018).

\section{Depression as a Mediator}

Depression was examined as a potential mediator of the relationship between IPV victimization and substance use as well as antisocial behavior $\left(\mathrm{H}_{5}\right.$ and $\left.\mathrm{H}_{6}\right)$. Two models demonstrated mediation: the effect of $\mathrm{C}-\mathrm{IPV}$ on illicit drug use and the effect of IP-IPV-Physical on marijuana use were no longer significant after the introduction of depression. This provides partial support only for Hypothesis 5 and for general strain theory (Agnew, 2001). It is possible that C-IPV or physical IP-IPV as objective strains may lead to depression as a subjective strain, influencing substance use. The use of illicit substances such as marijuana has been posited to be a coping response in an effort to diminish the pains associated with IPV and depression (Cloutier et al., 2019). as a coping mechanism. Further research is necessary to establish such claims, as temporal order is uncertain here and a limitation of the study.

Partial mediation was also established for several other models that included depression. For example, depression was associated with antisocial behavior, with higher scores increasing the odds of antisocial behavior across all models. This suggests that antisocial behavior may be influenced by depression, a finding that has been supported (Heerde et al., 
2019) and underscores the importance of effective mental health treatment. The same was true for problematic drinking, marijuana use, and illicit drug use. Thus, strain from IPV, whether offline or online, may lead to depression that, in turn, impacts maladaptive coping in an effort to ameliorate feelings of despondence or dejection. Continued research is needed here with longitudinal studies to establish causality.

\section{Gender and Maladaptive Behaviors}

The final hypotheses postulated that females who experienced C-IPV and IP-IPV would be more likely to engage in substance use compared to males $\left(\mathrm{H}_{7}\right)$ while males with these experiences would be more likely to engage in antisocial behavior compared to females $\left(\mathrm{H}_{8}\right)$. Although Hypothesis 7 was not supported as males were more likely than females to engage in problematic drinking, marijuana use, and illicit drug use, males were also found to be more likely to engage in antisocial behavior, thereby providing support for Hypothesis 8 . Such findings may point to a general pattern of deviance that has been noted for males, particularly white college-aged males (Buckman et al., 2011; Esteban McCabe et al., 2007; Walters et al., 2009), which can be a byproduct of masculinity and "doing gender" (West \& Zimmerman, 1987; p. 126) and societal norms that encourage men to engage in substance abuse rather than result of IPV victimization experiences alone. Further research on male victimization and maladaptive behaviors, as well as female victimization and such correlates, is therefore warranted. Expanding on psychosocial outcomes and other behaviors could lend insight into how males and females may experience and cope differently with stress.

Overall, victims of partner violence, whether electronic or in-person, reported higher rates of maladaptive behaviors than non-victims, which is consistent with the literature (e.g. Bennett et al., 2011; Devries et al., 2014; Lu et al., 2018; Timmons Fritz et al., 2018; Van Ouytsel et al., 2016). Depressive symptomology was also important and served as a better correlate than anger, which could point to a strain reaction that has been less studied in criminological research yet in line with psychological work. Further, it is notable that there were no gender differences in depression, especially considering women have been found to be almost twice as likely to have depression compared to men (Brody et al., 2018), which may be due to the larger proportion of females in this study. As such, it is important to have future studies that have more of a gender balance. It is possible that differential emotional responses exist that impact maladaptive behaviors. Therefore, we call for research to examine a range of responses in the future with male only and female only samples to discern what gender differences in maladaptive coping may be due to strain responses associated with IPV (i.e., C-IPV and IP-IPV) experiences. This may provide insight into how gender beliefs and socialization factor into these areas. In this study, bivariate and multivariate tests demonstrated that strain was related to victimization experiences and maladaptive behaviors, yet the evidence for strain as a mediator was weak. Future research should use mediation as well as moderation analyses to investigate the role of strain in longitudinal samples and include other potential mediators, such as social support, that may impact victimization and maladaptive coping links.

\section{Limitations and Future Research}

Despite the contributions of this study, there were some limitations. First of all, a measure for multiple victimization experiences (e.g., C-IPV and IP-IPV) was not included to test for cumulative effects of IPV on behavioral associations. Though it is important to consider the impact of individual experiences on maladaptive behaviors, future research should examine the effects of cumulative victimization experiences as they can compound trauma. Likewise, it is possible that strain manifests in different and complex ways. Therefore, future research should examine various subjective strains (e.g. depression, anger, and fear) and differing conceptualizations along with their additive and interactive effects. Additionally, more conservative measures of victimization may lead to different results, which can be useful for investigating abusive experiences rather than aggression more broadly. This may impact the observed relationships. Given that this study relied on a cross-sectional sample and is correlational, future research should focus on establishing temporal order for victimization and maladaptive behaviors or examine exacerbated effects via longitudinal studies, particularly for worrisome outcomes such as problematic drinking, illicit drug use, and violence. Furthermore, administrating questionnaires in a randomized order to prevent the possibility of order effects and including a measure to account for social desirability bias should both be considered for future work. The risk of Type I error is also high due to the number of analyses conducted in this study. Finally, it should be noted that this study's findings cannot be generalized to a broader population given that the sample consisted predominantly of White, heterosexual females from the United States with subclinical levels of depression. Our results may vary with the inclusion of a more diverse samples, such as persons from other demographic backgrounds, non-college students, or those institutionalized or under care of social support and healthcare providers. 
Our findings also point to future research in IPV and marijuana use. Marijuana use is a behavior commonly classified as deviant, yet it has been growing in social acceptance and has also been used as a medicinal treatment for PTSD and other challenging disorders (Hill, 2015), though the research in this area is mixed as marijuana use may have lasting negative physical and mental health effects (Arria et al., 2016; Keith et al., 2015). As countries increasingly adopt legislation centering on medicinal and recreational use, patterns that show the substance being used as a treatment strategy rather than something problematic may emerge. Therefore, research employing samples from regions where less restrictive marijuana policies exists would help us understand whether people adapt it as a treatment strategy to victimization and/or depressive symptomology, and whether it works or is associated with challenges.

\section{Research and Policy Implications}

The current study indicates that C-IPV resembles IP-IPV in terms of sharing similar correlates and that strain in the form of depression more so than anger may mediate some links between victimization and maladaptive behavior. This research points to potential behavioral outcomes associated with threatening online and offline environments, suggesting that harmful exchanges in the virtual world may have consequences that parallel IP-IPV. Coping with adverse circumstances can be difficult, and it is important that practitioners and researchers move to treat C-IPV more seriously as a type of IPV that can affect those on the receiving end. Some victims may experience strain and adapt to contexts characterized by stress in damaging ways. For instance, individuals may engage in harmful practices as a response to strain (e.g. depression) they experience due to C-IPV and IP-IPV, which aids to reduce negative feelings as a sort of grief relief (Agnew, 2001). Such adaptations may be helpful in releasing feelings of depression or other emotions in the shortterm but can have consequences or exacerbate symptoms and circumstances in the long-run. In other instances, individuals experience strain but desist or refrain from crime as a form of resilience. These areas are worthy of future exploration as it is essential to discover why a small portion of the persons who experience C-IPV and IP-IPV engage in destructive behavior and how this can be prevented by boosting resilience among individuals who experience such dangers. Researchers can explore mechanisms of providing social support through social networking sites (Dimond et al., 2011) as well as through in-person means (e.g. on college campuses, in domestic violence shelters, and within the Criminal Justice System) and work on building safety and protective factors in survivors. Researchers and community members also should address perpetration through education and other meaningful strategies to reduce all forms of IPV and the associated public health concerns.

As the results of this study indicate, IPV service providers should work to be inclusive of all types of IPV victimizations. C-IPV was related to problematic drinking, marijuana use, illicit drug use, and antisocial behavior, and depression partly mediated some of these relationships. Furthermore, it is important to consider that engaging in these harmful activities may place victims at risk for all forms of IPV victimization. Tailoring community outreach, prevention efforts, and intervention strategies so that they recognize C-IPV as an emerging health problem could expand the number of victims reached, and understanding the role depression plays in the link between victimization, substance use, and antisocial behavior can aid in disrupting the onset of behavioral issues that might harm one's health or that of others. Given that the study relied on a sample of young adults in college which is a place where romantic interests are explored, it is important that violence prevention providers and administrators working in this setting realize that electronic aggression occurs in intimate relationships and can have a serious impact on victims. As such, violence prevention educators and counseling service providers should be aware of C-IPV and IP-IPV, along with their associated outcomes so they are better equipped to address it. By recognizing various types of partner victimizations and their respective outcomes, we can seek to provide proactive remedies for maladaptive behaviors.

\section{References}

Agnew, R. (1992). Foundation for a general strain theory of crime and delinquency. Criminology, 30(1), 47-88. https://doi.org/10.1111/j.1745-9125.1992.tb01093.x

Agnew, R. (2001). Building on the foundation of general strain theory: Specifying the types of strain most likely to lead to crime and delinquency. Journal of Research in Crime \& Delinquency, 38(4), 319-361.

https://doi.org/10.1177/0022427801038004001

Arnett, J. J. (2000). Emerging adulthood: A theory of development from the late teens through the early twenties. American Psychologist, 55(5), 469-480. https://doi.org/10.1037/0003-066X.55.5.469 
Arria, A. M., Caldeira, K. M., Bugbee, B. A., Vincent, K. B., \& O'Grady, K. E. (2016). Marijuana use trajectories during college predict health outcomes nine years post-matriculation. Drug and Alcohol Dependence, 159, 158-165.

https://doi.org/10.1016/j.drugalcdep.2015.12.009

Baron, R. M., \& Kenny, D. A. (1986). The moderator-mediator variable distinction in social psychological research: Conceptual, strategic and statistical considerations. Journal of Personality and Social Psychology, 51(6), 1173-1182. https://doi.org/10.1037/0022-3514.51.6.1173

Baum, K., Catalano, S. M., Rand, M. R., \& Rose K. (2009). Stalking victims in the United States. Bureau of Justice Statistics. http://bjs.ojp.usdoj.gov/index.cfm?ty=pbdetail\&iid=1211

Bauman, S., \& Newman, M. L. (2013). Testing assumptions about cyberbullying: Perceived distress associated with acts of conventional and cyber bullying. Psychology of Violence, 3(1), 27-38. https://doi.org/10.1037/a0029867

Bennett, D. C., Guran, E. L., Ramos, M. C., \& Margolin, G. (2011). College students' electronic victimization in friendships and dating relationships: Anticipated distress and associations with risky behaviors. Violence and Victims, 26(4), 410429. https://doi.org/10.1891/0886-6708.26.4.410

Black, M. C., Basile, K. C. Basile, Breiding, M. J., Smith, S. G., Walters, M. L., Merrick, M. T., Chen, J., \& Stevens, M. R. (2011). The National Intimate Partner and Sexual Violence Survey (NISVS): 2010 summary report. National Center for Injury Prevention and Control, Centers for Disease Control and Prevention.

https://www.cdc.gov/violenceprevention/pdf/nisvs_report2010-a.pdf

Bocij, P. (2004). Cyberstalking: Harassment in the internet age. Praeger Publishers.

Borrajo, E., Gámez-Guadix, M., Pereda, N., \& Calvete, E. (2015). The development and validation of the cyber dating abuse questionnaire among young couples. Computers in Human Behavior, 48, 358-365.

https://doi.org/10.1016/j.chb.2015.01.063

Breiding M. J., Chen, J., \& Black, M. C. (2014). Intimate partner violence in the United States - 2010. National Center for Injury and Prevention, Centers for Disease Control and Prevention.

https://www.cdc.gov/violenceprevention/pdf/cdc_nisvs_ipv_report_2013_v17_single_a.pdf

Brody, D. J., Pratt, L. A. \& Hughes, J. P. (2018). Prevalence of depression among adults aged 20 and over: United States, 2013-2016 (NCHS Data Brief No. 303). National Center for Health Statistics.

https://www.cdc.gov/nchs/data/databriefs/db303.pdf

Broidy, L., \& Agnew, R. (1997). Gender and crime: A general strain theory perspective. Journal of Research in Crime and Delinquency, 34(3), 275-306. https://doi.org/10.1177/0022427897034003001

Buckman, J. F., Yusko, D. A., Farris, S. G., White, H. R., \& Pandina, R. J. (2011). Risk of marijuana use in male and female college student athletes and nonathletes. Journal of Studies on Alcohol and Drugs, 72(4), 586-591.

https://doi.org/10.15288/jsad.2011.72.586

Caldwell, J. E., Swan, S. C., \& Woodbrown, V. D. (2012). Gender differences in intimate partner violence outcomes. Psychology of Violence, 2(1), 42-57. https://doi.org/10.1037/a0026296

Cloutier, R. M., Kearns, N. T., Knapp, A. A., Contractor, A. A., \& Blumenthal, H. (2019). Heterogeneous patterns of marijuana use motives using latent profile analysis. Substance Use \& Misuse, 54(9), 1485-1498.

https://doi.org/10.1080/10826084.2019.1588325

Coker, A. L., Davis, K. E., Arias, I., Desai, S., Sanderson, M., Brandt, H. M., \& Smith, P. H. (2002). Physical and mental health effects of intimate partner violence for men and women. American Journal of Preventive Medicine, 23(4), 260268. https://doi.org/10.1016/S0749-3797(02)00514-7 
Coker, A. L., Smith, P. H., Bethea, L., King, M. R., \& McKeown, R. E. (2000). Physical health consequences of physical and psychological intimate partner violence. Archives of Family Medicine, 9(5), 451-457.

https://doi.org/10.1001/archfami.9.5.451

Connell, R. W. (1987). Gender and power: Society, the person, and sexual politics. Polity Press.

David-Ferdon, C., \& Hertz, M. F. (2007). Electronic media, violence, and adolescents: An emerging public health problem. Journal of Adolescent Health, 41(Suppl. 6), S1-S5. https://doi.org/10.1016/j.jadohealth.2007.08.020

Desmarais, S. L., Reeves, K. A., Nicholls, T. L., Telford, R. P., \& Fiebert, M. S. (2012). Prevalence of physical violence in intimate relationships, Part 1: Rates of male and female victimization. Partner Abuse, 3(2), 140-169.

https://doi.org/10.1891/1946-6560.3.2.140

Devries, K. M., Child, J. C., Bacchus, L. J., Mak, J., Falder, G., Graham, K., Watts, C., \& Heise, L. (2014). Intimate partner violence victimization and alcohol consumption in women: A systematic review and meta-analysis. Addiction, 109(3), 379-391. https://doi.org/10.1111/add.12393

Dimond, J. P., Fiesler, C., \& Bruckman, A. S. (2011). Domestic violence and information communication technologies. Interacting with Computers, 23(5), 413-421. https://doi.org/10.1016/j.intcom.2011.04.006

Ellison, L. (2001). Cyberstalking: Tackling harassment on the Internet. In D. Wall (Ed.), Crime and the Internet (pp. 141151). Routledge.

Exner-Cortens, D., Eckenrode, J., \& Rothman, E. (2013). Longitudinal associations between teen dating violence victimization and adverse health outcomes. Pediatrics, 131(1), 71-78. https://doi.org/10.1542/peds.2012-1029

Fedina, L., Lynne Holmes, J., \& Backes, B. L. (2018). Campus sexual assault: A systematic review of prevalence research from 2000 to 2015. Trauma, Violence, \& Abuse, 19(1), 76-93. https://doi.org/10.1177/1524838016631129

Follingstad, D. R., Rutledge, L. L., Berg, B. J., Hause, E. S., \& Polek, D. S. (1990). The role of emotional abuse in physically abusive relationships. Journal of Family Violence, 5(2), 107-120. https://doi.org/10.1007/BF00978514

Gutierres, S. E., \& Van Puymbroeck, C. (2006). Childhood and adult violence in the lives of women who misuse substances. Aggression and Violent Behavior, 11(5), 497-513. https://doi.org/10.1016/j.avb.2006.01.010

Heerde, J. A., Curtis, A., Bailey, J. A., Smith, R., Hemphill, S. A., \& Toumbourou, J. W. (2019). Reciprocal associations between early adolescent antisocial behavior and depressive symptoms: A longitudinal study in Victoria, Australia and Washington State, United States. Journal of Criminal Justice, 62, 74-86. https://doi.org/10.1016/j.jcrimjus.2018.09.003

Hill, K. P. (2015). Medical marijuana for treatment of chronic pain and other medical and psychiatric problems: A clinical review. JAMA, 313(24), 2474-2483. https://doi.org/10.1001/jama.2015.6199

Hinduja, S., \& Patchin, J. W. (2007). Offline consequences of online victimization: School violence and deliquency. Journal of School Violence, 6(3), 89-112. https://doi.org/10.1300/J202v06n03_06

Hughes, T., Esteban McCabe, S., Wilsnack, S. C., West, B. T., \& Boyd, C. J. (2010). Victimization and substance use disorders in a national sample of heterosexual and sexual minority women and men. Addiction, 105(12), 2130-2140. https://doi.org/10.1111/j.1360-0443.2010.03088.x

James, L. R., \& Brett, J. M. (1984). Mediators, moderators, and tests for mediation. Journal of Applied Psychology, 69(2), 307-321. https://doi.org/10.1037/0021-9010.69.2.307

Katz, J. E., \& Aakhus, M. (2002). Perpetual contact: Mobile communication, private talk, public performance. Cambridge University Press. 
Kaufman, J. M. (2009). Gendered responses to serious strain: The argument for a general strain theory of deviance. Justice Quarterly, 26(3), 410-444. https://doi.org/10.1080/07418820802427866

Kaysen, D., Dillworth, T. M., Simpson, T., Waldrop, A., Larimer, M. E., \& Resick, P. A. (2007). Domestic violence and alcohol use: Trauma-related symptoms and motives for drinking. Addictive Behaviors, 32(6), 1272-1283. https://doi.org/10.1016/j.addbeh.2006.09.007

Keith, D. R., Hart, C. L., McNeil, M. P., Silver, R., \& Goodwin, R. D. (2015). Frequent marijuana use, binge drinking and mental health problems among undergraduates. The American Journal on Addictions, 24(6), 499-506.

https://doi.org/10.1111/ajad.12201

Kelly, H., \& Segall, L. (2015, June 19). Google bans revenge porn. CNN.

http://money.cnn.com/2015/06/19/technology/google-bans-revenge-porn/index.html

Kohut, A., Wike, R., Horowitz, J. M., Simmons, K., Poushter, J., Barker, C., Bell, J., \& Gross, E. M. (2011). Global digital communications: Texting, social networking popular worldwide. Pew Global Attitudes Project, Pew Research Center. https://www.pewresearch.org/global/2011/12/20/global-digital-communication-texting-social-networking-popularworldwide/

Lin, W.-H., Cochran, J. K., \& Mieczkowski, T. (2011). Direct and vicarious violent victimization and juvenile delinquency: An application of general strain theory. Sociological Inquiry, 81(2), 195-222. https://doi.org/10.1111/j.1475-

682X.2011.00368.x

Lu, Y., Van Ouytsel, J., Walrave, M., Ponnet, K., \& Temple, J. R. (2018). Cross-sectional and temporal associations between cyber dating abuse victimization and mental health and substance use outcomes. Journal of Adolescence, 65, 1-5. https://doi.org/10.1016/j.adolescence.2018.02.009

Lydon, A., Bonds-Raacke, J., \& Cratty, A. D. (2011). College students' Facebook stalking of ex-partners. Cyberpsychology, Behavior, and Social Networking, 14(12), 711-716. https://doi.org/10.1089/cyber.2010.0588

Marganski, A. (2013). The extent of virtual relationship violence and perspectives on punishment: Do gender or nationality matter? Future Internet, 5(3), 301-316. https://doi.org/10.3390/fi5030301

Marganski, A. \& Fauth, K. (2013). Socially interactive technology and contemporary dating: A cross-cultural exploration of deviant behaviors in the modern, evolving technological world. International Criminal Justice Review, 23(4), 357-377. https://doi.org/10.1177/1057567713513797

Marganski, A., \& Melander, L. (2018). Intimate partner violence victimization in the cyber and real world: Examining the extent of cyber aggression experiences and its association with in-person dating violence. Journal of Interpersonal Violence, 33(7), 1071-1095. https://doi.org/10.1177/0886260515614283

Marsden, R. (2016, February 19). Samule Eto'o wins case to a publication of former lover's 'revenge porn' book. Bleacher Report. http://bleacherreport.com/articles/2617901-samuel-etoo-wins-case-to-ban-publication-of-formerlovers-revenge-porn-book

McCabe, S. E., Morales, M. Cranford, J. A., Delva, J., McPherson, M. D., \& Boyd, C. J. (2007). Race/ethnicity and gender differences in drug use and abuse among college students. Journal of Ethnicity in Substance Abuse, 6(2), 75-95. https://doi.org/10.1300/J233v06n02_06

Melander, L. A. (2010). College students' perceptions of intimate partner cyber harassment. Cyberpsychology, Behavior, and Social Networking, 13(3), 263-268. https://doi.org/10.1089/cyber.2009.0221

O'Leary, D. K. (1999). Psychological abuse: A variable deserving critical attention in domestic violence. Violence and Victims, 14(1), 3-23. https://doi.org/10.1891/0886-6708.14.1.3 
Overstreet, N. M., Willie, T. C., \& Sullivan, T. P. (2019). Stigmatizing reactions versus general negative reactions to partner violence disclosure as predictors of avoidance coping and depression. Journal of Interpersonal Violence, 34(8), 1734-1752. https://doi.org/10.1177/0886260516653753

Palmer, R. S., McMahon, T. J., Rounsaville, B. J., \& Ball, S. A. (2010). Coercive sexual experiences, protective behavioral strategies, alcohol expectancies and consumption among male and female college students. Journal of Interpersonal Violence, 25(9), 1563-1578. https://doi.org/10.1177/0886260509354581

Peskin, M. F., Markham, C. M., Shegog, R., Temple, J. R., Baumler, E. R., Addy, R. C., Hernandez, B., Cuccaro, P., Gabay, E. K., Thiel, M., \& Tortolero Emery, S. (2017). Prevalence and correlates of the perpetration of cyber dating abuse among early adolescents. Journal of Youth and Adolescence, 46(2), 358-375. https://doi.org/10.1007/s10964-016-0568-1

Radloff, L. S. (1977). The CES-D Scale: A self-report depression scale for research in the general population. Applied Psychological Measurement, 1(3), 385-401. https://doi.org/10.1177/014662167700100306

Reed L. A., Tolman, R. M., \& Ward, L. M. (2016). Snooping and sexting: Digital media as a context for dating aggression and abuse among college students. Violence Against Women, 22(13), 1556-1576.

https://doi.org/10.1177/1077801216630143

Reed, L. A., Tolman, R. M., \& Ward, L. M. (2017). Gender matters: Experiences and consequences of digital dating abuse victimization in adolescent dating relationships.

Journal of Adolescence, 59, 79-89. https://doi.org/10.1016/j.adolescence.2017.05.015

Rennison, C. M. \& Welchans, S. (2000). Intimate partner violence. U.S. Department of Justice, Office of Justice Programs, Bureau of Justice Statistics. https://www.bjs.gov/content/pub/pdf/ipv.pdf

Riegger, M., \& Valiente, A. (2014, October 17). Obsessive Ex's cyberstalking gets man fired, arrested. ABC News. http://abcnews.go.com/US/obsessive-exs-cyberstalking-man-fired-arrested/story?id=26256346

Sargent, K. S., Krauss, A., Jouriles, E. N., \& McDonald, R. (2016). Cyber victimization, psychological intimate partner violence, and problematic mental health outcomes among first-year college students. Cyberpsychology, Behavior, and Social Networking, 19(9), 545-550. https://doi.org/10.1089/cyber.2016.0115

Sev're, A. (2002). Fleeing the house of horrors. University of Toronto Press.

Shorey, R. C., Cornelius, T. L., \& Bell, K. M. (2008). A critical review of theoretical frameworks for dating violence: Comparing the dating and marital fields. Aggression and Violent Behavior, 13(3), 185-194.

https://doi.org/10.1016/j.avb.2008.03.003

Southworth, C., Finn, J., Dawson, S., Fraser, C., \& Tucker, S. (2007). Intimate partner violence, technology, and stalking. Violence Against Women, 13(8), 842-856. https://doi.org/10.1177/1077801207302045

Spitzberg, B. H., \& Hoobler, G. (2002). Cyberstalking and the technologies of interpersonal terrorism. New Media \& Society, 4(1), 71-92. https://doi.org/10.1177/14614440222226271

Straus, M. A., Hamby, S. L., Boney-McCoy, S., \& Sugarman, D. B. (1996). The revised Conflict Tactics Scale (CTS2): Development and preliminary psychometric data. Journal of Family Issues, 17(3), 283-316.

https://doi.org/10.1177/019251396017003001

Stubbs-Richardson, M., Sinclair, H. C., Goldberg, R. M., Ellithorpe, C. N., \& Amadi, S. C. (2018). Reaching out versus lashing out: Differences in experiences with and responses to bullying in high school. American Journal of Criminal Justice, 43(1), 39-66. https://doi.org/10.1007/s12103-017-9408-4

Suler, J. (2004). The online disinhibition effect. CyberPsychology \& Behavior, 7(3), 321-326.

https://doi.org/10.1089/1094931041291295 
Taylor, Z. E., Doane, L. D., \& Eisenberg, N. (2014). Transitioning from high school to college: Relations of social support, ego-resiliency, and maladjustment during emerging adulthood. Emerging Adulthood, 2(2), 105-115.

https://doi.org/10.1177/2167696813506885

Temple, J. R., Jeong Choi, H., Brem, M., Wolford-Clevenger, C., Stuart, G. L., Fleschler Peskin, M., \& Elmquist, J. (2016). The temporal association between traditional and cyber dating abuse among adolescents. Journal of Youth and Adolescence, 45(2), 340-349. https://doi.org/10.1007/s10964-015-0380-3

Thompson, R. S., Bonomi, A. E., Anderson, M., Reid, R. J., Dimer, J. A., Carrell, D., \& Rivara, F. P. (2006). Intimate partner violence prevalence, types, and chronicity in adult women. American Journal of Preventive Medicine, 30(6), 447-457. https://doi.org/10.1016/j.amepre.2006.01.016

Timmons Fritz, P. A., Clark-Crumpton, J., Daskaluk, S., \& Wilson, L. (2018). Electronic partner aggression victimization: Its frequency and relation to offline partner aggression and psychological functioning. Partner Abuse, 9(4), 421-438. https://doi.org/10.1891/1946-6560.9.4.421

Tjaden, P., \& Thoennes, N. (2000). Full report of the prevalence, incidence, and consequences of violence against women: Findings from the National Violence Against Women Survey. U.S. Department of Justice, Office of Justice Programs, National Institute of Justice and Centers for Disease Control and Prevention.

https://www.ncjrs.gov/pdffiles1/nij/183781.pdf

Turkle, S. (2011). Alone together: Why we expect more from technology and less from each other. Basic Books.

Van Ouytsel, J., Ponnet, K., Walrave, M., \& Temple, J. R. (2016). Adolescent cyber dating abuse victimization and its associations with substance use, and sexual behaviors. Public Health, 135, 147-151.

https://doi.org/10.1016/j.puhe.2016.02.011

Van Ouytsel, J., Torres, E., Jeong Choi, H.., Ponnet, K., Walrave, M., \& Temple, J. R. (2017). The associations between substance use, sexual behaviors, bullying, deviant behaviors, health, and cyber dating abuse perpetration. The Journal of School Nursing, 33(2), 116-122. https://doi.org/10.1177/1059840516683229

Walters, G. D., Felix, C. M., \& Reinoehl, R. (2009). Replicability and cross-gender invariance of a two-dimensional model of antisociality in male and female college students. Personality and Individual Differences, 46(7), 704-708.

https://doi.org/10.1016/j.paid.2009.01.028

West, C., \& Zimmerman, D. H. (1987). Doing gender. Gender \& Society, 1(2), 125-151.

https://doi.org/10.1177/0891243287001002002

Wordsworth, M. (2015, June 28). 'Stalker apps' and GPS allow domestic violence abusers to discover hidden refuges. ABC. http://www.abc.net.au/news/2015-06-28/stalker-apps-and-gps-endanger-domestic-violence-victims/6570882

Wright, M. F. (2015). Cyber victimization and perceived stress: Linkages to late adolescents' cyber aggression and psychological functioning. Youth \& Society, 47(6), 789-810. https://doi.org/10.1177/0044118X14537088

Wright, M. F., \& Li, Y. (2012). Kicking the digital dog: A longitudinal investigation of young adults' victimization and cyber-displaced aggression. Cyberpsychology, Behavior, and Social Networking, 15(9), 448-454.

https://doi.org/10.1089/cyber.2012.0061

Wyckoff, J. P., Buss, D. M., \& Markman, A. B. (2019). Sex differences in victimization and consequences of cyber aggression: An evolutionary perspective. Evolutionary Behavioral Sciences, 13(3), 254-264.

https://doi.org/10.1037/ebs0000150

Ybarra, M. L. (2004). Linkages between depressive symptomatology and Internet harassment among young regular Internet users. CyberPsychology \& Behavior, 7(2), 247-257. https://doi.org/10.1089/109493104323024500 
Zapor, H., Wolford-Clevenger, C., Elmquist, J., Febres, J., Shorey, R. C., Brasfield, H., Leisring, P. A., \& Stuart, G. L. (2017). Psychological aggression committed through technology: A study with dating college students. Partner Abuse, 8(2), 127-145. https://doi.org/10.1891/1946-6560.8.2.127

Zweig, J. M., Dank, M., Yahner, J., \& Lachman, P. (2013). The rate of cyber dating abuse among teens and how it relates to other forms of teen dating violence. Journal of Youth and Adolescence, 42(7), 1063-1077.

https://doi.org/10.1007/s10964-013-9922-8

Zweig, J. M., Lachman, P., Yahner, J., \& Dank, M. (2014). Correlates of cyber dating abuse among teens. Journal of Youth and Adolescence, 43(8), 1306-1321. https://doi.org/10.1007/s10964-013-0047-x

\section{Correspondence to:}

Lisa A. Melander

Department of Sociology, Anthropology, \& Social Work

204 Waters Hall

Manhattan, KS 66506

United States

Email: Imeland(at)ksu.edu

Editorial record: First submission received on December 14, 2018. Revisions received on August 8, 2019 and December 6, 2019. Accepted for publication on January 29, 2020.

Editor in charge: Kristian Daneback

\section{About Authors}

Lisa A. Melander, Ph.D., is an Associate Professor in the Department of Sociology, Anthropology, and Social Work at Kansas State University. Her primary research interests include intimate partner violence, cyber aggression, and women's incarceration.

Alison J. Marganski, Ph.D. is Associate Professor \& Director of Criminology in the Department of Anthropology, Criminology, \& Sociology at Le Moyne College in Syracuse, NY. Her research explores intimate partner violence, sexual violence, mass murder, and other transgressions from interdisciplinary and intersectional perspectives. She is also interested in violence prevention and using research to inform victim- and offender-related services. 